International Journal of Politics and Security (IJPS)

\title{
Antarktika Antlaşmalar Sistemi Kapsamında Çevre Örgütlerinin Rolü: Antarktika ve Güney Okyanusu Koalisyonu Örneği
}

\section{Yazar(lar) / Author(s): Elçin DORUK}

Kaynak / Source: International Journal of Politics and Security (IJPS) / Cilt. 3 / Say1. 3 / Ekim. 2021, ss. 369-389.

DOI: $10.53451 /$ ijps. 866970

\section{Geliş Tarihi / Date of Arrival : : 23.01.2021 \\ Kabul Tarihi / Date of Acceptance: 30.03.2021}

\section{Bu Makaleye Atıf İçin / To cite this article:}

Doruk, Elçin. "Antarktika Antlaşmalar Sistemi Kapsamında Çevre Örgütlerinin Rolü: Antarktika ve Güney Okyanusu Koalisyonu Örneği”. International Journal of Politics and Security (IJPS), Cilt. 3, Say1. 3, 2021, ss.369-389, DOI: 10.53451/ijps.866970

Bu makalenin tüm hakları International Journal of Politics and Security (IJPS) Dergisi'ne aittir. Önceden yazılı izin almadan hiçbir iletişim, kopyalama ya da yayın sistemi kullanılarak yeniden yayımlanamaz, çoğaltılamaz, dağıtılamaz, satılamaz veya herhangi bir şekilde kamunun ücretli/ücretsiz kullanımına sunulamaz. Akademik amaçlı alıntılar bu kuralın dışındadır. Yazıda belirtilen fikirler yalnızca yazarına/yazarlarına aittir. 


\title{
Antarktika Antlaşmalar Sistemi Kapsamında Çevre Örgütlerinin Rolü: Antarktika ve Güney Okyanusu Koalisyonu Örneği
}

\author{
Elçin DORUK*
}

\begin{abstract}
Özet
Çevre örgütleriyle devletler ve hükümetler arası kurumlar arasındaki ilişki, devletlerin üstünlük sağlamak için çevre örgütlerini araçsallaştırmaya çalıştığı, çevre örgütlerinin ise daha önce devletler tarafindan sahip olunan işlevleri devraldiğı stratejik bir etkileşim olarak isimlendirilebilir. Bu kapsamda birçok çevre sivil toplum örgütünden oluşan Antarktika ve Güney Okyanusu Koalisyonu'nun, Antarctic and Southern Ocean Coalition (ASOC), küresel Antarktika siyasetinde üstlendiği rol zaman içinde gelişmiştir. ASOC'nin varlığı büyüyen ekolojik kayglar, bunları ele almak için gelişen hukuki araçlar ve kitayı yöneten Antarktika Antlaşmalar Sistemi'nin gelişiminden oluşan daha geniş bir çerçeveye yerleşir. Bu bağlamda bu çalışmada ASOC ve ulus devletler arasindaki ilişki, kıtayı yöneten sistemi şekillendiren Antarktika Antlaşması İstişare Toplantılarının işleyişi kapsamında ele alınmaktadır. Değerlendirme sürecinde toplant raporlarından, yönetim planlarından ve politika belgelerinden yararlanilırken, elde edilen data nitelik ve nicelik olarak analiz edilmektedir. Günümüzde gittikçe artan çevresel hassasiyetler ASOC'nin kıta siyasetindeki etkinliğini öne çıkarmaktadır.
\end{abstract}

Anahtar Kelimeler: Antarktika Antlaşmalar Sistemi, Çevre Örgütleri, Antarktika ve Güney Okyanusu Koalisyonu, Antarktika Siyaseti, Çevresel Muhafaza.

\section{The Role of Environmental Organizations in Antarctic Treaty System: The Case of the Antarctic and Southern Ocean Coalition}

\begin{abstract}
The relationship between environmental organizations and states and intergovernmental organizations can be named as a strategic interaction in which states try to instrumentalize environmental organizations to gain superiority, and environmental organizations take over the functions previously held by states. In this regard, the role played by the Antarctic and Southern Ocean Coalition (ASOC), which consists of many environmental NGOs, in the politics of Antarctica evolved in time. The existence of the ASOC takes place in a broader framework of growing ecological concerns, the evolving legal tools to address them, and the development of the Antarctic Treaty System, which governs the continent. In this context, this study aims to analyze the relationship between ASOC and nation-states in the context of the Antarctic Treaty Consultation Meetings, which shape the system governing the continent. The methodology is mainly based on the evaluation of meeting reports, management plans, and policy documents in terms of quality and quantity. Environmental sensitivities increasing according to the expected result from the general structure highlight the effectiveness of ASOC in Antarctic affairs.
\end{abstract}

Keywords: The Antarctic Treaty System, Environmental NGOs, Antarctic, and Southern Ocean Coalition, The Politics of Antarctica, Environmental Conservation.

\footnotetext{
* Araştırma Görevlisi Doktor, Yaşar Üniversitesi, Ekonomi Bölümü, elcin.doruk@yasar.edu.tr, ORCID ID: 0000-0002-8547-7443
}

Date of Arrival: 23.01 .2021 - Date of Acceptance: 30.03.2021. 
IJPS, 2021: 3(3):369-389

International Journal of Politics and Security, 2021: 3(3):369-389

\section{Giriş}

Antarktika Antlaşması (AA), Antarctic Treaty (AT), 1958'de Soğuk Savaş koşullarında müzakere edilirken çevrenin korunması önemli bir öncelik değildi. Antlaşmanın temel amacı Antarktika'yı barışa adamak ve kıta üzerinde askerî harekâtı önlemekti. Buna ilaveten AA kıta üzerinde nükleer denemeleri, radyoaktif atık malzemelerin kıtaya götürülmesini yasaklayan ve kıtadaki canlı kaynakların korunması ve muhafazası için önlemler alınmasını tavsiye eden hükümler de içeriyordu. ${ }^{1}$ Uzun bir süre boyunca Antarktika'daki balinaların ve fokların popülasyonu yoğun avcılık faaliyetiyle ciddi bir şekilde istismar edildi ve birçok yerel tür yok olma tehlikesiyle karşı karşıya kaldı. Bu durum bazı ekonomik ve çevresel kaygıları artırdı. Artan endişeler neticesinde 1946 yılında belirli bir konuda Antarktik ekosistemini korumaya yönelik ilk yasal düzenleme olan Uluslararası Balina Avcılığının Düzenlenmesi Sözleşmesi, International Convention for the Regulation of Whaling (ICRW), imzalanmıştır. ${ }^{2} 1964$ yılına gelindiğinde Antarktika Flora ve Faunasının Korunması için Mutabık Kalınan Önlemler, the Agreed Measures for the Conservation of Antarctic Flora and Fauna (CAFF), kabul edilmiş ve bunu 1972'de Antarktik Ayı Balıklarını Koruma Sözleşmesi, the Convention for the Conservation of Antarctic Seals (CCAS), izlemiştir. ${ }^{3}$

1991 yılında imzalanan ve kıta üzerindeki insan aktivitelerini düzenlemeyi hedefleyen Antarktika Antlaşması Çevre Koruma Protokolü (Çevre Protokolü), The Protocol on Environmental Protection to the Antarctic Treaty, AA'ya getirilen en kapsamlı ek olmuştur. ${ }^{4}$ $\mathrm{Bu}$ bağlamda geçen yaklaşık atmış yıllık süreç içinde AA, kıtanın çevresel muhafazasına yönelik gereksinimler doğrultusunda gelişmiş ve Antarktika Antlaşmalar Sistemi (AAS) olarak isimlendirilen sofistike bir hukuki sisteme evrilmiştir. Bu hukuki sistemin en önemli özelliğinin uluslararası örgütlerin çatısı altında değil, doğrudan devletlerin önderliğinde kurulmuş ve geliştirilmiş olmasıdır. AAS içerisinde yer alan devletlerin sayısı bugün elli dörde ulaşmıştır. ${ }^{5}$ Taraf devletler kıta yönetiminin belirlendiği yıllık Antarktika Antlaşması İstişare

\footnotetext{
1 AA, Madde IX, paragraf 1 (f), Antarktika Antlaşması'nın tam metni için bknz.: https://www.ats.aq/e/antarctictreaty.html, (09.01.2021).

${ }^{2}$ Uluslararası Balina Avcılığının Düzenlenmesi Sözleşmesi resmi metni için bknz.: https://iwc.int/convention, (09.01.2021).

${ }^{3}$ Mutabık Kalınan Önlemler'in detayları için bknz.: https://ats.aq/e/faflo.html, (09.01.2021); Antarktik Ayı Balıklarını Koruma Sözleşmesi resmi metni için için bknz.: https://ats.aq/e/key-documents.html, (09.01.2021).

${ }^{4}$ Antarktika Antlaşması Çevre Koruması Protokolü tam metni için bknz.: https://www.ats.aq/e/protocol.html, (16.01.2021).

${ }^{5}$ Taraf devletlerle ilgili detaylı bilgi için bknz.: https://www.ats.aq/devAS/Parties?lang=e, (08.01.2021).
} 
Toplantılarında, The Antarctic Treaty Consultative Meetings (ATCMs), bir araya gelerek kitayı ilgilendiren meseleleri gündemlerine alırlar. ${ }^{6}$

AAS'nin çevresel muhafazaya yönelik yetkinliğiyle ilgili tartışmalar, Birleşmiş Milletler İnsan Çevresi Konferansı (Stockholm Konferansı) kapsamında gelişen çevre savunuculuğunun ilgisini kıta çevresinin korunmasına yönlendirmiştir. Kıtanın uluslararası yönetiminin şekillendiği ATCM'lerin kapalı kapılar ardında yapıldığı dönemde, başta Amerika Birleşik Devletleri (ABD) merkezli Hukuk ve Sosyal Politika Merkezi, Center for Law and Social Policy (CLASP), ve Sierra Kulübü, The Sierra Club, olmak üzere, çevre sivil toplum örgütlerinin AAS'yle ilişkisi toplantı dışında delegelere görüş belgesi dağıtmakla sınırlıydı. ${ }^{7}$ 1970'lerin sonunda çevre örgütlerinin temsilcileri ulusal delegasyonlarla ilgili ATCM'lere katılmaya davet edildi. CLASP'tan bir çevre avukatı olan James Barnes 1978'de Antarktika ve Güney Okyanus Koalisyonu'nu, Antarctic and Southern Ocean Coalition (ASOC), kurdu. Günümüzde ASOC Antarktika Antlaşması Sekretaryası ve diğer koalisyon üyeleriyle iş birliği içinde çalışan ve aidat ödeyen yirmi öne çıkan yerel ve uluslararası üye kuruluş tarafından desteklenmektedir. ${ }^{8}$

Artan çevresel endişeler neticesinde 1998 y1lında yürürlüğe giren Çevre Protokolü Antarktika'yı bir defa daha bilime ve barışa adarken, kıta üzerindeki insan faaliyetlerini düzenlemeyi amaçlamıştır. ${ }^{9}$ Çevre Protokolü, öngördügü hükümlerin uygulanmasıyla bağlantılı olarak ATCM'ye tavsiyelerde bulunmak üzere uzman bir danışma organı olarak Çevre Koruma Komitesi'ni, the Committee for Environmental Protection (CEP), kurmuştur. ${ }^{10}$ CEP, ATCM ile birlikte her yıl toplanmaktadır. ${ }^{11}$ Akademik literatürde daha önceki döneme kıyasla 1998'de Çevre Protokolü’nün yürürlüğe girmesinden sonra kıtanın çevresel muhafazasının geliştirilmesinde çevre örgütlerinin çalışmaları hakkında nispeten daha az araştırma yer almıştır. ${ }^{12} \mathrm{Bu}$ bağlamda bu çalışma, birçok çevre sivil toplum örgütünü

\footnotetext{
${ }^{6}$ Dışişleri Bakanlığı Antarktika Antlaşması web sayfasında ve Dış İlişkiler Terminolojisi içinde consultative kelimesi istişare olarak çevrilmiş ve Antarktika Antlaşması İstişare Toplantıları olarak nitelendirilmiştir. Bu çalışma içinde de aynı kullanım yer alacak ve kısaca İstişare Toplantıları olarak belirtilecektir. Toplantı raporlarına verilen referanslarda ise ATCM kısaltması kullanılacaktır.

${ }^{7}$ Toplantı detayları için bknz.: https://ats.aq/e/atcm.html, (09.01.2021).

${ }^{8}$ ASOC üyelerinin detayları için bknz.: https://www.asoc.org/about/coalition-members, (24.11.2020).

${ }^{9}$ Protokol detayları için bknz.: https://www.ats.aq/e/protocol.html, (09.01.2021).

${ }^{10} \mathrm{CEP}$ detayları için bknz.: https://www.ats.aq/devAS/CEP/Authorities?lang=e, (10.01.2021).

${ }^{11}$ Toplantı dokümanları için bknz.: https://www.ats.aq/devAS/Meetings/DocDatabase?lang=e, (09.01.2021).

${ }^{12}$ Adrian Howkins, "Politics and environmental regulation in Antarctica: a historical perspective," in Handbook on the Politics of Antarctica, eds. Klaus Dodds, Alan D. Hemmings and Peder Roberts (Cheltenham: Edward Elgar
} 
bünyesinde barındıran ASOC'nin küresel Antarktika siyasetinde oynadığı rolün gelişimini nitelik ve nicelik olarak inceleyecektir. ASOC'nin varlığı büyüyen ekolojik kaygılar, bunları ele almak için gelişen hukuki araçlar ve kıtayı yöneten AAS'nin gelişiminden oluşan daha geniş bir çerçeveye yerleşir. Çevre örgütleriyle devletler ve hükümetler arası kurumlar arasındaki ilişki, devletlerin üstünlük sağlamak için çevre örgütlerini araçsallaştırmaya çalıştığı, çevre örgütlerinin ise daha önce devletler tarafından sahip olunan işlevleri devraldığı 'stratejik bir etkileşim' olarak isimlendirilebilir.

$\mathrm{Bu}$ araştırmada ASOC ve ulus devletler arasındaki ilişki, kıtanın uluslararası yönetimini şekillendiren AAS işleyişi kapsamında ele alınacaktır. Değerlendirme sürecinde toplantı raporlarından, yönetim planlarından ve politika belgelerinden yararlanılacak, elde edilen data nitelik ve nicelik olarak analiz edilecektir. Araştırma kapsamında bu çalışma ASOC'nin ATCM ve CEP toplantılarına katılımına ve yaptığı bilimsel yayınlara odaklanacaktır. ASOC faaliyetlerinin şekillendirilmesini, zamanlamasını ve içeriğini ele alarak kıta çevresinin korunmasını teşvik etmek için üstlendiği çeşitli roller değerlendirmeye alınacaktır. $\mathrm{Bu}$ noktadaki esas soru çevre örgütlerinin Antarktika çevresinin muhafazasını iyileştirmede ne kadar etkili olduğudur. Bu bağlamda bu çalışmada ASOC üzerinden AAS içinde çevre örgütlerinin etkinliğinin tanımlanması amaçlanmıştır.

\section{AAS İşleyişinde Çevre Savunuculuğun Gelişimi}

Çevre örgütlerinin çalışmaları 1980 Deniz Canlı Kaynaklarının Korunması Hususunda Sözleşme'nin Convention on the Conservation of Antarctic Marine Living Resources (CCAMLR) müzakerelerinde, kıtada mineral kaynak kullanımının önünü açacak olan Antarktik Maden Kaynakları Faaliyetlerinin Düzenlenmesine İlişkin Sözleşme’nin, Convention on the

\footnotetext{
Publishing, 2017), 337-350; M. Clark, "The Antarctic Environmental Protocol: NGOs in the Protection of Antarctica," in Environmental NGOs in World Politics, eds. T. Prince and M. Finger (New York: Routledge, 1994), 160-185; P. Convey, K.A. Hughes and T. Tin. "Continental Governance and Environmental Management Mechanisms Under the Antarctic Treaty System Sufficient for the Biodiversity Challenges of this Century?," Biodiversity 13 (2012): 3-4; R. Herr, "The Changing Roles of Non-governmental Organizations in the Antarctic Treaty System," in The Effectiveness and Legitimacy of the Antarctic Treaty System, eds. O.S. Stokke and D. Vidas (Cambridge: Cambridge University Press, 1996), 91-119; L. Kimball, "The Role of Non-Governmental Organizations in Antarctic Affairs," in The Antarctic Legal Regime, eds. C.C. Joyner and S.K. Chopra (Dordrecht: Martinus Nijhoff, 1988), 33-63; R.M. Roura, "The Antarctic and Southern Ocean Coalition ASOC," in The Encyclopedia of the Antarctic, ed. B. Riffenburgh (New York: Routledge, 2007), 41-43; Tina Tin, "'Environmental advocacy in the Antarctic Treaty System - a personal view from the 2000s", The Polar Journal 3 , no. 2 (2013): 415-430; Erin Neufeld, Jessica O’Reilly, Rupert Summerson and Tina Tin, "Valuing Antarctica: emerging views from international studies," in Antarctic Futures, eds. Tina Tin, Daniela Liggett, Patrick T. Maher, Machiel Lamers (Dordrecht: Springer, 2014), 233-252.
} 
Regulation of Antarctic Mineral Resource Activities (CRAMRA), reddedilmesinde ve ardindan Çevre Protokolü'nün geliştirilmesi ve onaylanmasında etkili olmuştur. ${ }^{13}$ Çevre savunucuları ATCM toplantılarında hem ulusal delegasyonların bir parçası olarak 'içeriden' hem de protesto ve lobi faaliyetleriyle 'dışarıdan' çalışmıştır. Ayrıca kamu bilincini ve kamuoyunun gelişimini teşvik etmek için yüksek profilli tanıtım kampanyaları yürütmüşlerdir. Örneğin Greenpeace 1987 ve 1992 yılları arasında çevresel suiistimalleri belgeleyerek ve duyurarak Antarktika'daki "Dünya Parkı" olarak isimlendirdiği uluslararası üssünü korumuştur. ASOC ise 1988'de CCAMLR genel kurulu ve 1991'de ATCM ve CCAMLR Bilimsel Komitesi'nde gözlemci statüsünü elde etmiştir.

Antarktika'y1 ilgilendiren çevresel meseleler 1991'de Çevre Protokolü'nün imzalanmasından sonra farklı bir döneme girmiştir. Ulusal çevre örgütlerinin Antarktik sorunlarına katılımı önemli ölçüde azalmıştır. ${ }^{14}$ Buna rağmen ASOC, Protokol'ün ve ona EkVI Çevresel Acil Durumlardan Doğan Sorumluluk 'un, Liability Arisin from Environmental Emergencies, onaylanıp uygulanmasını, kıtadaki turizm ve biyoürünleştirme faaliyetlerinin düzenlenmesini teşvik ederek AAS içinde aktif olmaya devam etmiştir. ${ }^{15}$ Protokol onaylandıktan sonra ise Antarktika kamusal sahneyi 'terk etmiştir'. Hem kamuoyu hem de çevre örgütleri artık savaşın 'kazanıldığını' ve kıtanın 'kurtarıldığııı' varsaydığından çevre savunucularının çalışmaları başka yerlerdeki daha acil sorunlara yönelmiştir.

2020 y1lı itibariyle ASOC'nin internet sitesinde listelenmiş dokuz personel üyesi vardır. Bu üyelerinin çoğu yüksek öğrenim derecelerine ve hukuk, uluslararası politika, çevre politikası biyoloji ve yer bilimleri dahil olmak üzere çeşitli uzmanlık alanlarına sahiptirler. ${ }^{16}$ Çoğunluğu Antarktika ve/veya çevre konularında deneyimlidir. Örneğin 1994 yılında Güney Okyanusu'nda balina avcılığı karşıtı kampanya yürüten Greenpeace gemisindeki mürettebatın yarısından çoğu bilimsel, teknik veya yönetimsel beceriler konusunda oldukça deneyimliydi.

13 Deniz Canlı Kaynaklarının Korunması Hususunda Sözleşme resmi metni için bknz.: https://www.ccamlr.org/en/organisation/camlr-convention-text, (16.01.2021); Antarktik Maden Kaynaklar1 Faaliyetlerinin Düzenlenmesine İlişkin Sözleşme resmi metni için bknz.: https://www.ats.aq/e/keydocuments.html, (18.01.2021).

${ }^{14}$ C.J. Bastmeijer, "Implementing the Antarctic Environmental Protocol: Supervision of Antarctic Activities," Tilburg Foreign Law Review, no. 1 (2003): 407-438.

${ }^{15}$ R.M. Roura, "The Antarctic and Southern Ocean Coalition - ASOC," in The Encyclopedia of the Antarctic, ed. B. Riffenburgh (New York: Routledge, 2007), 41-43; Ek-VI için bknz.: https://www.ats.aq/e/liability.html, (21.01.2021).

${ }^{16}$ Detaylar için bknz.: https://www.asoc.org/about/team, (11.01.2021). 
Hepsinin çevreyle güçlü duygusal bağları vardı. Birçoğu için gezegendeki son vahşi yaşam alanına uzanan yolculuk aynı zamanda arınma, içe dönüş ve gündelik olandan uzaklaşma yolculuğu demekti. Ayrıca Antarktika'nın yanında tüm insanlığın çıkarını da korumak bir ayricalıktı. ${ }^{17}$

Bir diğer örnek 2013 yılında anketler üzerinden büyük bir araştırma çalışmasının parçası olarak, ASOC ile yürütülen daha kapsamlı bir araştırmadır. ${ }^{18}$ Çalışma kapsamında 9. Dünya Yaban Hayatı Kongresi'ndeki Vahşi Yaşam Yönetimi Semineri'ne katılan ASOC kampanyacıları, yönetim kurulu üyeleri ve katılımcılarıyla kamuoyunun Antarktika algısı ve bunun nasıl yönetilmesi gerektiği üzerine bir çevrimiçi anket yürütmüştür. Verilen yüz on beş yanıtın tümü Antarktika'ya el değmemiş doğası ve dünya iklim sisteminin ayrılmaz bir parçası olarak öncelik verirken hiçbiri kıtayı bir turizm merkezi veya insan kullanımı için potansiyel bir mineral kaynak rezervi olarak değerlendirmemiştir. Antarktika 'hayranlık uyandıran bir kıta', 'tefekkür için bir yer' ve “insanlığın doğaya farklı açılardan bakmasını sağlayacak bir sembol" olarak isimlendirilmiştir. ${ }^{19}$ Bahsedilen örnekler Antarktik ilişkilerinde yer alan çevre savunucularının kişisel profillerini de ortaya koymaktadır.

\section{1. Çevre Savunuculuğunun Yeri ve Zamanı}

Antarktika'nın çevresel muhafazasına yönelik çevre savunuculuğu temelde yıl boyunca yürütülmektedir. Çevre örgütleri yıllık ATCM'ler beklenirken hükümetler ve ilgili kuruluşlar arasında lobi yapar, kilit paydaşların konumları hakkında bilgi toplamaya devam eder ve hedeflerine ulaşmak için farklı forumlar aracılığıyla üzerlerinde baskı kurmanın yollarını bulur. İlgili konularda etkinliklere, toplantılara katılır ve düzenler. Bilimsel araştırma, bilime dayalı çevre yönetimi ve bilimle ilgili lojistiğin çevresel etkileri Antarktika'daki insan faaliyetlerinin yönetiminin merkezinde yer alır. Bu doğrultuda çevre örgütlerinin temsilcileri bilimsel faaliyetleri yürütme ve bilim insanlarını ve bilime dayalı karar alma sürecini etkileme gibi

\footnotetext{
${ }^{17}$ R.M. Roura and Ibáñez E. del Acebo, "Percepción ambiental en el Oceáno Austral: La Antártida real, imaginaria y posible," in El habitar urbano: Pensamiento, imaginación y límite, ed. Ibáñez E. del Acebo (Buenos Aires: Universidad del Salvador, 2000), 555-599.

${ }^{18}$ T.Tin, K. Bastmeijer, J. O'Reilly and P. Maher, "Public Perception of the Antarctic Wilderness: Surveys from an Educated, Environmentally Knowledgeable European Community," in Science and Stewardship to Protect and Sustain Wilderness Values: Ninth World Wilderness Congress Symposium; November 6-13, 2009; Meridá, Yucatán, Mexico, comps. A. Watson, J. Murrieta-Saldivar and B. McBride, 109-117. ${ }^{19}$ a.g.e.
} 
konularda da aktif olarak rol almaktadır. ${ }^{20}$ Ayrıca medya çalışmaları yürütmede, çevresel konuları duyurmada, kamuoyunu etkilemede ve halk desteği oluşturmada çok aktiftirler. Buna bir örnek Greenpeace Yeni Zelanda şubesinin üyelerinden Ross Denizi'nin korunması hakkında Başbakana yazmalarını istemesidir. ${ }^{21}$ Bu noktada basın bültenleriyle etkinliklerin ve yayınların duyurulması gibi geleneksel eylemlerin yanında internet siteleri, blog siteleri, Facebook, Instagram ve Twitter gibi sosyal medya hesaplarındaki düzenli güncellemeler ve tanınmış kişiler tarafından kampanyalara verilen destek günümüzde en etkili araçlar olarak kullanılmaktadır. ${ }^{22}$

Çevre örgütleri CEP'in çalışmalarının önemli bir parçası haline gelen oturumlar arası tartışmalara da katılır. Bu tartışmalar genellikle teknik konulara odaklanır. Bunların çoğu, Antarktika Özel Yönetimli Alanlar, Antarctic Specially Managed Areas (ASMAs), Antarktika Özel Koruma Alanları, Antarctic Specially Protected Areas (ASPAs), ve Yönetim Planlarının revizyonu ile ilgili olmakla birlikte çevresel izleme için koordineli bir yaklaşımın geliştirilmesi, bireysel çevresel etki değerlendirmeleri ve Antarktika'nın vahşi değerlerinin korunmasının uygulanmasına ilişkin rehberliğin geliştirilmesi gibi konular da yer alır. ${ }^{23} \mathrm{Bu}$ tartışmalar CEP toplantılarında veya ATCM'lerde ortamda olan siyasi gerilimden daha uzak olma avantajına sahiptir ve potansiyel olarak teknik konuların daha yaratıcı ve derinlemesine araştırılmasına olanak tanır. Çevre sivil toplum örgütlerinin toplantılar arası tartışmalara katkıları genellikle tartışmaların nihai raporlarına ve daha sonra CEP veya ATCM'lere yönelik tavsiyelerine dahil edilir.

Taraflar ve gözlemciler, bir sonraki ATCM ve CEP toplantısı için birkaç ay önceden sunulacak belgeleri hazırlamaya başlar. Çevre örgütleri bu hazırlık sürecinin erken aşamalarında taraflarla ilişki kurarak çevre sorunlarının çözümüne yönelik potansiyel desteği artırabilir ve alınacak kararları etkileyebilir. Hükümet ile yerel sivil toplum örgütlerinin arasında uzun süredir devam eden ilişkilerin olduğu kimi ülkelerde, bahsedilen hazırlık

\footnotetext{
${ }^{20}$ T. Tin, R. Roura and M. Perrault, "Enhancing the Environmental Legacy of the International Polar Year 20072008," Eos Transactions AGU 87, no. 52 (2006).

${ }^{21}$ Detaylar için bknz.: Greenpeace NZ, https://wayback.archive-it.org/9650/20200424150737/http://p3raw.greenpeace.org/new-zealand/en/take-action/Take-action-online/Save-the-Last-Ocean/, (08.12.2020).

22 Örnekler için bknz.: The Antarctica Blog, http://antarcticablog.blogspot.com/,\%20http://antarcticocean.org/supporters/, (22.11.2020).

23 Örnek olarak bknz.: Australia, "Subsidiary Group on Management Plans": France, "Environmental Monitoring and Reporting; Czech Republic, "Response to the Comments"; New Zealand, "Intersessional Report", https://www.ats.aq/devAS/ToolsAndResources/AntarcticTreatyDatabase?lang=e, (08.12.2020).
} 
sürecinde bu yerel örgütlere de danışılır ve temsilcileri genellikle ulusal delegasyonlara dahil edilir. $^{24}$

\section{2. Çevre Savunuculuğu ve İlgili Sorunlar}

Yıllık ATCM ve CEP toplantılarında çevre örgütlerinin resmi 'görevi' bildirilerini ve araştırmalarını sunmak ve çevreyi ilgilendiren hususlarda tartışmalara katkıda bulunmaktır. Bununla birlikte çevre örgütlerinin büyük bir kısmı toplantı aralarında ya da özel toplantılarda gayri resmi tartışmalara katılma ve ittifak kurma yoluyla faaliyetlerini devam ettirir. ${ }^{25}$ Perde arkasında örgütlerin temsilcileri farklı ülkelerin bakış açıları hakkında bilgi toplar ve kilit delegelerin fikirlerini etkilemek için çalışır. Ulusal delegasyonlarda yer alan çevre savunucuları genellikle çevresel öncelik olan konuların kendi hükümetlerinin gündeminde yer almasına için uğraşır. Genel çerçevede resmi toplantılar haricinde devletler arasında süregelen tartışmalar anlaşmazlıkların dile getirildiği, tartışmalı konuların ele alındığı ve muhalefetin mümkün olduğu kadar bastırıldığı önemli olaylar olarak düşünülmelidir. ${ }^{26} \mathrm{Bu}$ bağlamda delegelerin bu gayri resmi süreçlerde, resmi tartışmalar sırasında ortaya çıkabilecek istenmeyen sürprizleri önceden engellemenin veya en aza indirmenin provasını yaptığ1 söylenebilir.

ASOC'nin 1985-2019 aralığında AAS işleyişinde gerçekleştirilen resmi toplantılarda sunduğu önbilimsel makaleler ve bilgi notlarının konulara göre dağılımı şu şekilde sıralanabilir: turizm (32 makale), Çevre Protokolün'ün uygulanması (21), deniz koruma alanları (9), iklim değişikliği (21), denizcilik (20), altyapı geliştirme ve vahşi doğayı koruma (12). Öne çıkan diğer konular ise şu şekilde sıralanabilir: biyoürünleştirme, deniz gürültüsü, insan faaliyetlerinin çevresel etkileri, denetimler ve sorumluluk (Tablo 1). ASOC tarafindan sunulan resmî belgelerde yer almayan ancak çevre savunuculuğu kapsamında ele alınan diğer konular ise şunlardır: buzul altı çevrelerin korunması, Albatrosların ve Petrellerin Korunması Antlaşması'nın, the Agreement on the Conservation of Albatrosses and Petrels (ACAP), onaylanması ve Güney Okyanusu Balina Koruma Alanı'nda yürütülen balina avcılığı. ${ }^{27}$

\footnotetext{
${ }^{24}$ Tina Tin, "Environmental advocacy in the Antarctic Treaty System - a personal view from the 2000s", 420.

25 J. O'Reilly, The Technocratic Antarctic: An Ethnography of Scientific Expertise and Environmental Governance.

${ }^{26}$ Tina Tin, "Environmental advocacy in the Antarctic Treaty System - a personal view from the 2000s", 421.

${ }^{27}$ ASOC, "Report of the Antarctic and Southern Ocean Coalition (ASOC7) IP 84," ATCM XXII, The Hague, May 25-June 05, (1998); ASOC, "Report of the Antarctic and Southern Ocean Coalition (ASOC) IP 21," SATCM VII,
} 
Tablo 1: ASOC'nin Resmi Toplantılarda Sunduğu Bilgi Notu Ve Önbilimsel Makalelerin Konulara Göre Dağglımi ${ }^{28}$

\begin{tabular}{|c|c|}
\hline Konular & $\begin{array}{c}\text { 1985-2019 aralı̆ı̆nda ASOC'nin resmi } \\
\text { toplantılarda sunduğu bilgi notu ve önbilimsel } \\
\text { makale sayısı }\end{array}$ \\
\hline Turizm & 32 \\
\hline Çevre Protokolü uygulaması & 21 \\
\hline Deniz koruma alanları & 9 \\
\hline İklim değişikliği & 21 \\
\hline Denizcilik (Kutup Kodu, gemi trafik yönetimi vb.) & 20 \\
\hline Altyapı geliştirme ve vahşi doğayı koruma & 12 \\
\hline
\end{tabular}

Koalisyon üyesi sivil toplum örgütlerinin hangi konular üzerinde yoğunlaştığ1 aşağıdakiler dahil birçok faktöre bağlıdır:

- ATCM ve CEP için stratejik çalışma planları hazırlamak başta olmak üzere AAS kapsamında tartışılan konular;

- Birleşmiş Milletler Deniz Hukuku Sözleşmesi, United Nations Law of the Sea (UNCLOS), veya turistik amaçlı gemi kazaları gibi küresel ve bölgesel gelişmeler;

- Çevre sivil toplum örgütlerinin ve fon sağlayıcıların ilgisi; (Örneğin ASOC ve bazı üye kuruluşlarının Antarktika Okyanusu İttifakı'na, the Antarctic Ocean Alliance, dahil olması deniz koruma alanlarına yönelik çevre savunuculuğunu artırmıştır). ${ }^{29}$

- Teknik uzmanlık ve örgüt temsilcilerinin bireysel ilgisi. (Örneğin turist davranış1 konusunda Dr. Ricardo Roura, çevresel etki değerlendirmeleri konusudan Dr Alan Hemmings ve krill avcılığı konusunda Dr. Rodolfo Werner gibi ASOC uzmanlarının akademik araştırmalarından resmi toplantılarda sunulmak üzere birçok ASOC bilgi notu ve önbilimsel makalesi geliştirilmiştir). ${ }^{30}$

\footnotetext{
Tromsø, September 11-15, (2000); ASOC, "Report of the Antarctic and Southern Ocean Coalition (ASOC) IP 66 Rev.1," ATCM XXVII, Cape Town, May 24-June 04, (2004).; ASOC, "Report of the Antarctic and Southern Ocean Coalition (ASOC) IP 85," ATCM XXXV, Hobart, June 11-20, (2012a).; Albatrosların ve Petriklerin Korunması Anlaşması resmi metni için bknz.: https://www.acap.aq, (18.01.2021).

28 AA Sekretaryası internet sitesinde yer alan toplantı veri tabanına dayanılarak hazırlanmıştır, https://www.ats.aq/devAS/Meetings/DocDatabase?lang=e, (09.01.2021).

${ }^{29}$ Tina Tin, "Environmental advocacy in the Antarctic Treaty System - a personal view from the 2000s", 421.

${ }^{30}$ ASOC, "Management Implications of Tourist Behaviour IP 67," ATCM XXXVI, Brussels, May 20-29, (2013c); ASOC, "Implications of Antarctic Krill Fishing in ASMA No. 1 - Admiralty Bay IP 54," ATCM XXXV, Hobart, June 11-20, (2012b); ASOC, "Strengthening the CEE Process IP 84," ATCM XXX, New Delhi, April 30-May 11, (2007a).
} 
Çevre örgütlerinin hazırladığı bilgi notları ve önbilimsel makaleler AA'ya taraf ülkelerin ATCM öncesi gündeme gelecek bir konuyla ilgili ön bilgi sahibi olmasına olanak sağlar, toplantı sırasında sözlü olarak sunulur, tarafların ilgi düzeyine bağlı olarak bu esnada tartışılır ve ATCM son raporuna kaydedilerek sistem belgeleri havuzunda saklanır. ${ }^{31} \mathrm{Bu}$ bağlamda AAS'de uzman gözlemci statüsündeki tek hükümet dişı kurum olan ASOC, uluslararası toplantılara gönderdiği bilim insanları ve politika uzmanlarıyla Antarktika'nın geleceğinin şekillendirilmesinde rol oynamaktadır.

\section{AAS İşleyişinde Üstlenilen Çevre Savunuculuğu Rolleri}

Çevre sivil toplum örgütlerinin başarısı hedef kitlelerine ve sorunlarına uygun farklı yöntemler kullanmadaki esnekliklerine bağlıdır. Roura ve Tin'e göre Antarktika'yı ilgilendiren meseleleri hedef alan çevre örgütleri zaman içinde bazıları Jung arketiplerine benzeyen farklı roller üstlenmiştir. ${ }^{32}$ Bunlar sırasıyla şu şekilde isimlendirilebilir: gözlemci, paydaş ve teknik danışman, savunucu ve ileri görüşlü. ${ }^{33}$

\subsection{Gözlemci}

Buna göre ASOC'nin öncelikli rolü bağımsız bir gözlemci olarak Antarktika'da yürütülen faaliyetleri izlemek, AAS gündemine müdahil olmak, alternatif gündemler oluşturulması için baskı yapmak, çevresel suiistimalleri izlemek ve bunları dünyanın geri kalanına rapor etmektir. ${ }^{34} \mathrm{Bu}$ rol 2000'li yıllara kadar sürdürülmüştür. Koalisyon bünyesindeki çevre örgütleri bilgi notları, ECO isimli haber bültenleri ve lobi faaliyetleri aracılığıyla turizmin düzenlenmesi ve deniz koruma alanlarının kurulması gibi konuları kapsayan Çevre Protokolü Ek VI hususunda anlaşmaya varılmasını sağlamıştır. ${ }^{35}$ Protokolün yenilikçi hükümlerinin geri çekilmesini eleştiren çevre örgütleri, münferit projelerin çevresel etki değerlendirmeleri hakkında yorum da yapmıştır. Kıtanın çevresel muhafazasının kapsamlı bir şekilde sağlanması her zaman temel amaçları olmuştur. ${ }^{36}$ Taraf devletlerin özel olarak ele

\footnotetext{
${ }^{31}$ Tina Tin, "Environmental advocacy in the Antarctic Treaty System - a personal view from the 2000s", 421.

${ }^{32}$ R.M. Roura and T. Tin, "Strategic Thinking and the Antarctic Wilderness: Contrasting Alternative Futures," in Antarctic Futures Human Engagement with the Antarctic Environment, eds. T. Tin, D. Ligget, P. Maher and M. Lamers (Dordrecht: Springer, 2014): 253-271.

33 Tina Tin, "Environmental advocacy in the Antarctic Treaty System - a personal view from the 2000s", 420.

34 a.g.e.

${ }^{35}$ Ek detayları için bknz.: https://www.ats.aq/e/liability.html, (11.11.2020).

36 Örnek olarak 1998, 2005 ve 2006 yıllarından ASOC tarafindan ATCM'ye sunulan raporlara bknz.: https://www.ats.aq/devAS/Meetings/DocDatabase?lang=e, (21.12.2020).
} 
almak veya harekete geçmek istemedikleri konuları hedef alan çevre savunucuları böylece zorunlu olarak 'muhalif' bir rol üstlenmişlerdir. ${ }^{37}$ CRAMRA müzakerelerinden sonra olduğu gibi geleneksel kamu protestoları bir daha gerçekleşmese de çevre savunucularının sözlü protestoları medyada veya ECO'larda yine de 'iğneleyici' olabilmiştir. ${ }^{38}$ Genellikle müzakere masasının zıt taraflarında yer aldıklarından, taraf devletler ile çevre örgütleri arasındaki ilişki her zaman mesafeli olmuştur. Hatta bazı ulusal delegeler ASOC üyelerinden 'kaçınırlar' 39 'Sessiz kayıtsızlık' taraf devletlerin çevre savunucuları tarafından gündeme getirilen sorunları görmezden gelmek için sıklıkla kullandıkları etkili bir diplomatik araçtır. Nadir durumlarda taraf devletler ile çevre örgütleri resmi toplantılar sırasında doğrudan 'karşı karşıya' gelmişlerdir. Bununla birlikte son toplantı raporlarında kullanılan kibar diplomatik dil, bu tür 'olayların' hepsinin değilse de çoğunun izlerini silebilmiştir. ${ }^{40}$

Çevre savunucuları bazı durumlarda gözlemci yerine masal karakteri Pinokyo'ya doğru olanı yapması gerektiğini hatırlatan Jiminy Cricket karakterine daha yakın, biraz 'dırdırcı' bir rol üstlenirler. ${ }^{41}$ Örneğin yürürlüğe girmesinden günümüze kadar geçen süre boyunca çevre örgütleri Protokolün amacına saygı gösterilmesi, uygulamalarının yerine getirilmesi ve vahşi doğanın koruması gerekliliğini yorulmadan tekrarlamıştır. ${ }^{42}$ Yine de çevre örgütleri ne derece etkin olursa olsun nihayetinden yalnızca önerilerde bulunabilmekte, taraf devletleri karar almaya veya harekete geçmeye zorlayamamaktadır. Antarktika'nın çevresel muhafazasına ilişkin müzakerelerin tamamlanması ve karara varılması yıllar almakta ve potansiyel sonuçlar genellikle en az on yıl sonrasına kadar belli olmamaktadır. ${ }^{43} \mathrm{Bu}$ sebeple çevre örgütleri çalışmak zorunda oldukları uzun zaman dilimi boyunca hem biraz çeşitlilik sağlamak ve hem de farklı kilit oyuncuların duyarlılıklarından yararlanmak için bekçi köpeğinin 'amansız' rolü ile vicdanın 'metanetli' rolü arasında geçiş yaparlar. ${ }^{44}$

\footnotetext{
${ }^{37}$ R. Herr, "The Changing Roles of Non-governmental Organizations in the Antarctic Treaty System'.

${ }^{38}$ O. A. Orheim, N. Gilbert, "Managing the Antarctic Environment: The Evolving Role of the Committee for Environmental Protection," in Science Diplomacy. Antarctica, Science, and the Governance of International Spaces, eds. P.A. Berkman, M.A. Lang, D.W.H. Walton and O.R. Young (Washington, DC: Smithsonian Institution Scholarly Press, 2011), 209-221.

39 J. O'Reilly, The Technocratic Antarctica: An Ethnography of Scientific Expertise and Environmental Governance.

${ }^{40}$ Tina Tin, "Environmental advocacy in the Antarctic Treaty System - a personal view from the 2000s", 421-2.

41 a.g.e.

42 Örnekler için ASOC internet sitesinde yer alan raporlara bknz.: https://www.asoc.org/explore/reports, (18.12.20201).

43 a.g.e.

44 a.g.e.
} 


\subsection{Paydaş ve Teknik Danışman}

Belirli durumlarda sivil toplum örgütleri taraf devletler ile eşit paydaşlar olarak çalışır. Yürütülen çalışmalar sonucu hazırlanan belgeler taraf bir ülke aracılığıyla toplantılarda sunulabilir. Örneğin İngiltere, Almanya, İspanya ve Norveç’in Dünya Vahşi Yaşam Fonu, World Wild Found (WWF), ile iklim değişikliğine yönelik çevresel muhafaza planlama araçları raporu 2014 yılındaki ATCM toplantısında sunulmuştur. ${ }^{45}$ ASOC stratejik çevresel değerlendirme kavramı veya kara tabanlı turizm tesisleri hakkında bilgi sağlamak gibi taraf devletlerden gelen taleplere yanıt verebilir. Bunlara ilaveten çevre örgütleri ATCM veya CEP ihtiyaçlarını karşılamaya yönelik girişimlerde bulunabilir. Örneğin çevresel konurlarla ilgili detaylı tartışmaların yapılmasına olanak sağlayan Antarktika Antlaşması Uzmanlar Toplantısı'nın, Antarctic Treaty Meetings of Experts (ATMEs), 2010 y1lındaki iklim değişikliğinin etkileri konulu buluşmasında kapsamlı bir Antarktika iklim değişikliği iletişim planı geliştirilmesi tavsiye edilmiştir. ${ }^{46} \mathrm{Bu}$ noktada ASOC bir taslak plan hazırlamak için inisiyatif almış ve çalışmaların daha fazla ilerleyebilmesi için ortak finansman sağlamıştır.

AAS bünyesinde sayg1 ve kabul görmek isteyen ASOC ilk günden itibaren üyelerinin uzmanlığından yararlanmıştır. ${ }^{47}$ Koalisyon bünyesindeki çevre örgütleri güçlü bir teknik uzmanlık temelini korumuş, uzmanlık alanları ve akademik araştırmalar kapsamında talep edilmese de teknik danışmanlık yapmıştır. Bu tavsiyeler, öncesinde yürütülen ölçülü bir lobicilik faaliyetiyle önemli ölçüde tartışılabilmekte ve nihai raporlara dahil edilebilmektedir. Bazen ise sessizce kayıtsızlıkla karşılanmaktadır. ${ }^{48}$

\subsection{Savunucu}

Belirtildiği üzere çevre örgütleri tarafından yayımlanan ve Antarktika’yı ilgilendiren müzakerelerde dağıtılan bir haber bülteni olan ECO, ATCM'lerde uzun süredir kullanılan bir savunuculuk aracı olmuştur. ECO, hükümetler arası toplantılarda ulusal delegelerin faydalanabileceği fikir ve alternatif öneriler sağlamayı ve medya için sorunları netleştirmeyi

\footnotetext{
45 ATCM XXXVII, “Antarctic Trial of WWF's Rapid Assessment of Circum-Arctic Ecosystem Resilience," Conservation Planning Tool, https://www.worldwildlife.org/publications/racer-rapid-assessment-of-circumarctic-ecosystem-resilience--2, (24.12.2020).

46 Tina Tin, "Environmental advocacy in the Antarctic Treaty System - a personal view from the 2000s", 423.

${ }^{47}$ M. Clark, "The Antarctic Environmental Protocol: NGOs in the Protection of Antarctica"; Herr, "The Changing Roles of Non-governmental Organizations".

${ }^{48}$ Tina Tin, "Environmental advocacy in the Antarctic Treaty System - a personal view from the 2000s", 423.
} 
hedeflemektedir. ${ }^{49}$ Müzakerelerin kapalı kapılar ardında sürdürüldüğü dönemde sert eleştirilerin aracı olmuş ve şeffaflı̆̆ı savunmuştur. ${ }^{50}$ ECO 2000'lerde 'Antarktika satılık mı ?!' veya 'İnkarın sonu!' gibi kışkırtıcı başlıklarla ulusal çıkarları öne sürmüş, önce sunulan ama sonra geri çekilen makalelerle ilgili 'ilginç söylentilere' atıfta bulunmuş ve internetten kaldırılan ancak Antarktika araştırma istasyonunda Çevre Protokolü hükümlerinin ihlal edildiğini açıkça gösteren görüntülere işaret etmiştir. ${ }^{51}$ ECO’nun kullandığı dil yakıcı ve esprili olabilir. Örneğin CEP'e 'Antarktik gölünde yeni keşfedilen omurgasız bir tür' olarak atıfta bulunmuştur: bacaklarını/üyelerinin büyük kısmı 'çoğu zaman hareketsiz' olan, 'beyni vücudun geri kalanından ayrılmış' ve 'ana faaliyeti çevreyi korumak adına yalnızca filtre koymak' olan şekilsiz bir 'jelatinimsi kütle' olarak tanımlamışıı. ${ }^{52}$ Ayrıca ilgili çizgi filmlerle ve Penguen Pablo karakteriyle toplantılarda bir çevre koruma 'parodisi' olarak yer almıştır. ${ }^{53}$ Diğer bir ifadeyle çevre örgütleri, ECO aracılı̆̆ıyla savunuculuk hedeflerine ulaşabilmek için bir bakıma 'saray soytarısı/maskarası' rolü benimsemiştir. ${ }^{54} \mathrm{Bu}$ roller üzerinden söylemlerine devam eden ECO güncel sayılarında özellikle CCAMLR ve muhafaza planlarının gelişimi, kıta turizmindeki tehlikeli artış, krill popülasyonu ve iklim değişikliği gibi konuları gündemine almaktadır. ${ }^{55}$

\section{4. İleri Görüşlü}

ASOC, AAS işleyişinde ileri görüşlü katılımcı rolüyle de yer alır. Henüz dikkate

\footnotetext{
${ }^{49}$ M. Clark, "The Antarctic Environmental Protocol: NGOs in the Protection of Antarctica".

${ }^{50}$ a.g.e.

${ }^{51}$ ECO, "ATCM XXV," Warsaw, September 13, 2002, no. 3; ECO, "A Publication of Non-Governmental Organizations at the XXVII Consultative Meeting of the Antarctic Treaty," Cape Town, May 24-June 4, 2004, no. 3; ECO, "A Publication of Non-Governmental Organizations at the XXX Consultative Meeting of the Antarctic Treaty," New Delhi, April 30-May 11, 2007a, no. 1; ECO, "A Publication of Non-Governmental Organizations at the XXXV Consultative Meeting of the Antarctic Treaty," Hobart, June 11-20, 2012a, no. 1.

${ }^{52}$ ECO, "A Publication of Non-Governmental Organizations at the XXX Consultative Meeting of the Antarctic Treaty," New Delhi, April 30-May 11, 2007b, no. 3.

${ }^{53}$ ECO, "ATCM XXV," Warsaw, September 13, 2002, no. 3; ECO, "A Publication of Non-Governmental Organizations at the XXIX Consultative Meeting of the Antarctic Treaty," Edinburgh, June 12-23, 2006, no. 3; ECO, "A Publication of Non-Governmental Organizations at the XXXV Consultative Meeting of the Antarctic Treaty," Hobart, June 11-20, 2012b, no. 2.

${ }^{54}$ Tina Tin, "Environmental advocacy in the Antarctic Treaty System - a personal view from the 2000s", 424.

${ }^{55}$ ECO, "A Publication of Non-Governmental Environmental Organizations at the XLII Consultative Meeting of the Antarctic Treaty, July 1-11, 2019; ECO, "A Publication of Non-Governmental Environmental Organizations at the XXXVI Commission on the Conservation of Antarctic Meeting Living Resources Meeting", Oct. 16-27, 2017; ECO "A Publication of Non-Governmental Environmental Organizations at the XXXIV Commission on the Conservation of Antarctic Meeting Living Resources Meeting, 21 Oct. 2015; ECO, " A Publication of NonGovernmental Environmental Organizations at the XXXVII Commission on the Conservation of Antarctic Meeting Living Resources Meeting", 8 Oct. 22-Nov. 2, 2018.
} 
gelmeyen konuları gündeme getirir ve taraflara sürekli olarak vizyon, uzun vadeli ve büyük ölçekli stratejiler ve proaktif katılım ihtiyacını hatırlatır. Örneğin çevre örgütleri AA tarafları veya diğer gözlemciler bu konuları henüz ciddiye almadan önce iklim değişikliği, deniz koruma alanları ve ticari turizmin gelişmesi hususunda belgeler sunmaya başlamıştır. ASOC, Çevre Protokolü’nün yürürlüğe girmesinden kısa bir süre sonra küreselleşmenin ekonomik baskılarına ve kıta üzerindeki 'sonsuz büyüme' arzusuna çoktan dikkatleri çekmiştir. Ticari turizm konusunun proaktif ve stratejik bir şekilde ele alınması ve kıtanın 'sürdürülebilir' geleceğine uygun olarak düzenlenmesi gerektiğinde 1 srar etmiştir. ${ }^{56}$ Tartışmalar bir sonuca varamadığında çevre örgütleri AAS'nin etik temellerini benimseme, Antarktika'yı bütünüyle koruma ve gelecek nesillere kalıcı bir çevresel miras bırakma ihtiyacını 'haykırmıştır'. ${ }^{57}$ Hükümetlerin ve ticari kuruluşlarının aksine çevre örgütleri, ulusal ve ticari kaygılar tarafından engellenmeden ticari kazancın, jeopolitik çıkarların ve ulusal prestijin karşısında bir tutum benimsemekte isteklidir. ${ }^{58} \mathrm{Bu}$ bağlamda ASOC, ATCM ve CEP toplantılarında en temel öncelik olarak çevresel muhafazayı savunan çevre örgütlerinin ortak sesini temsil etmektedir.

\section{AAS İşleyişinde Çevre Örgütlerinin Etkinliği}

Çevre örgütlerinin mineral kaynak araştırmasına yönelik yasak getirilmesine, çevreye zarar veren uygulamalara karşı kamuoyu oluşturulmasına ve Çevre Protokolü'nün uygunluğuna ve uygulanması ilişkin katkıları yadsınamaz. ${ }^{59}$ Bununla birlikte, çevresel muhafazaya verilen önem, çoğu zaman, çevre savunucularının çabalarının ulusal çıkarlarla ve kamuoyuyla doğru zamanda ve yerde kesişmesinden kaynaklanmaktadır ve bu durum çevre örgütlerinin etkinliğinin ölçülmesini ve değerlendirilmesini zorlaştırmaktadır. ${ }^{60}$ Diğer taraftan çevre örgütlerinin varlığı ve yokluğu arasındaki fark, Antarktika çevresinin korunması

\footnotetext{
${ }^{56}$ ASOC, "Tourism and Land-based Facilities in Antarctica IP 23 Rev.1", ATCM XXXII, Baltimore, April 06-17, 2009a; ASOC, "Making Tangible Progress on a Strategic Vision for Antarctic Tourism IP 80", ATCM XXXIV, Buenos Aires, June 20-July 01, 2011, 2010.

${ }^{57}$ ECO, "An NGO Newspaper Published for the XXII Antarctic Treaty Consultative Meeting," volume LXXXXV, Tromso, May 25-June 6, 1998, no. 3; ECO, "A Publication of Non-Governmental Organizations at the XXX Consultative Meeting of the Antarctic Treaty," New Delhi, April 30-May 11, 2007b, no. 3.

${ }^{58}$ Tina Tin, "Environmental advocacy in the Antarctic Treaty System - a personal view from the 2000s", 424.

${ }^{59}$ J.N. Barnes, "Legal Aspects of Environmental Protection in Antarctica," in The Antarctic Legal Regime, eds. C.C. Joyner and S.K. Chopra (Dordrecht: Martinus Nijhoff, 1988), 241-268; C.J. Bastmeijer, "Implementing the Antarctic Environmental Protocol: Supervision of Antarctic Activities," Tilburg Foreign Law Review, no. 1 (2003): 407-438; K. Suter, Antarctica: Private Property or Public Heritage? (London: Zed Books, 1991); P. Wapner, Environmental Activism and World Civic Politics (Albany: SUNY Press, 1996).

${ }^{60} \mathrm{~K}$. Dodds, "Governing Antarctica: Contemporary Challenges and the Enduring Legacy of the 1959 Antarctic Treaty", Global Policy, no. 1 (2010): 108-115; G. Nagtzaam, The Making of International Environmental Treaties. Neoliberal and Constructivist Analyses of Normative Evolution (Cheltenham: Edward Elgar, 2009).
} 
üzerindeki etkilerini anlamamıza olanak sağlar.

Belirtildiği üzere ASOC kıta yönetimini sağlayan ve Antarktika siyasetini şekillendiren AAS işleyişi kapsamında katıldığı toplantılarda düzenli olarak raporlar sunmaktadır. Önbilimsel makaleler ve bilgi notları olarak isimlendirilen bu sunumlar hem deniz hem de karasal alanlarda çevresel muhafazaya, çevre örgütlerinin kıta geleceğindeki rolüne, turizm, biyoürünleştirme ve iklim değişikliği gibi acil düzenleme gerektiren meselelere ve iş birliği kurulmasına odaklanmaktadır. Sistem kapsamında yer alan toplantılar ATCM, CEP, Antarktika Antlaşması Uzmanlar Toplantısı, Antarctic Treaty Meeting of Experts (ATME), ve Antarktika Antlaşması Özel İstişare Toplantısı, Special Antarctic Treaty Consultative Meeting (STCM), olarak isimlendirilmektedir. Bu kapsamda ASOC, 1985-2019 yılları arasında toplam 234 tane önbilimsel makale ve bilgi notu paylaşmıştır (Tablo 2). Dikkat çekici bir diğer nokta ise 1998 ile 2010 yılları arasında ASOC'nin, CEP'e 28 Antlaşma Tarafının 23'ünden daha fazla belge sunmuş olduğudur. ${ }^{61}$

Tablo 2: ASOC Tarafından Resmi Toplantılarda Sunulan Belgeler ${ }^{62}$

\begin{tabular}{|c|c|}
\hline Toplantı Türü ve Yıl Aralığı & $\begin{array}{c}\text { ASOC'nin sunduğu önbilimsel makaleler ve } \\
\text { bilgi notları sayısı }\end{array}$ \\
\hline ATCM (1991-2019) & 159 \\
\hline CEP $\left(2000 \_2019\right)$ & 58 \\
\hline STCM $(1985-1990)$ & 6 \\
\hline ATME $(2004-2010)$ & 11 \\
\hline
\end{tabular}

ASOC'nin toplantılarda sunduğu bu raporlara taraf devletlerin yaklaşımı değişiklik gösterir. Örneğin 2003 ve 2012 yılları arasındaki CEP sonuç raporlarına bakıldığında, belirtilen dönemde ASOC tarafindan sunulan 79 bilgi notunun yaklaşık yarısı taraf devletlerden herhangi bir yanıt alamamış, üçte biri ise bazı tartışmaları tetiklemeyi başarmıştır. ${ }^{63}$ Elbette bu durum taraf ülkelerin çevre örgütlerinin fikirlerini ne kadar benimsediğinin ya da uygulamaya aldığının tam olarak ölçülmesine olanak sağlamaz, ancak şunun bir göstergesidir:

- Çevre örgütlerinden gelen veriler kıta çevresinin korunmasıyla ilgili tartışmalar için temel teşkil eden materyalin önemli bir bölümünü oluşturmaktadır ve;

\footnotetext{
${ }^{61}$ P. Convey, K.A. Hughes and T. Tin, "Continental Governance and Environmental Manage- ment Mechanisms Under the Antarctic Treaty System Sufficient for the Biodiversity Challenges of this Century?" Biodiversity 13, no. 3-4 (2012): 241.

${ }^{62}$ AA Sekretaryası internet sitesinde yer alan toplantı veri tabanına dayanılarak hazırlanmıştır, https://www.ats.aq/devAS/Meetings/DocDatabase?lang=e, (10.01.2021).

${ }^{63}$ Tina Tin, "Environmental advocacy in the Antarctic Treaty System - a personal view from the 2000s", 425.
} 
- Çevre örgütlerinin bu toplantılara yaptığ katkılar olmadan, ulus devletlerin çevre konularına olan ilgisi ve bağlantılı tartışmalar önemli ölçüde azalacaktır. ${ }^{64}$

Bu bağlamda çevre örgütlerinin kıta yönetimine katılımı devletlerin dikkate almadığı veya destek vermediği konuların gündeme getirilmesinde özellikle etkili olmaktadır. Çevresel meselelerde en önemli destekçiler olarak çevre örgütlerinin ve savunucularının eksikliği, ilgili bir konunun gündeme gelememesine ya da gündemden kaybolmasına yol açabilir. Örneğin, 1991 ve 2019 yılları arasındaki toplantılarda küresel bir çevre sorunu olan gürültünün deniz memelileri üzerindeki etkilerine dair sadece 20 makale sunulmuştur ve bunların üçte birinin yazarı ASOC' dir. ${ }^{65}$ Benzer şekilde, ASOC, Antarktika'nın el değmemiş doğasının muhafazası konusunda az sayıdaki sözlü destekçiden biri olmuştur. Çevresel etki değerlendirmeleri, kıta turizmi ve bilimsel faaliyetler gibi insan aktivitelerinin çevreye etkisi ve genel olarak Çevre Protokolü’nün uygulanması konusuna dikkat çekmiştir. Bu hususlar, Yeni Zelanda, Hollanda ve ara sıra Avustralya ve Birleşik Krallık haricinde taraf devletlerden çok az destek alan konulardır. ${ }^{66} \mathrm{Bu}$ noktada çevre örgütleri bilimsel, teknik ve stratejik destekleriyle normalde dikkate gelmeyen konuları taraf devletlerin gündemine taşımaktadır.

Daha önce de bahsedildiği gibi çevre örgütlerinin çalışma yollarından biri medya araçları üzerinden kamuoyunu sürece dahil etmektir. Çevre savunucuları Antarktika'ya ilişkin hususlarda halkı bilgilendirmede aktif ve etkindir. ${ }^{67} \mathrm{Bu}$ bağlamda ASOC olmadan kıtanın çevresel muhafazasına ilişkin kamuoyu bilincinin ve katılımının önemli ölçüde daha düşük seviyede kalacağı söylenebilir.

Çevre örgütlerinin en önemli, yeri doldurulamaz ve dile getirilmeyen katkısı, kaçınılmaz olarak ulusal ve ticari çıkarlar çerçevesinde şekillenen kıta sisteminin yanında ‘ütopik' bir Antarktika vizyonunu sürdürmesidir. ASOC ve taraf devletlerin sunduğu raporlarda ele alınan konular niteliksel olarak karşılaştırıldığında, çevre örgütlerinin verilerini daha çok ortak miras kavramıyla ilişkilendirdiği ve daha iyi ve çevresel olarak sürdürülebilir

\footnotetext{
64 a.g.e.

65 Toplantı dokümanları arşivi için bknz.: https://www.ats.aq/devAS/Meetings/DocDatabase?lang=e, (19.01.2021).

66 a.g.e.

${ }^{67}$ ASOC günümüzdeki kamuoyu yaratmak için en etkili yollardan olan twitter ve instagram gibi sosyal medya hesaplarını aktif olarak kullanmaktadır. Hesap detaylarına koalisyonun internet sayfasından ulaşılabilir: https://www.asoc.org/explore/blog, (06.01.2021).
} 
bir gelecek vaadini hedeflediği görülebilir. ${ }^{68}$ Çevre savunucularının bu 'ileri görüşlü' söylemlerinin çoğu, elbette, ATCM ve CEP toplantılarında sessizlik ve kayıtsızlıkla karşılanmaktadır. Yine de bu söylemler, sessizce, çevresel muhafaza çıtasını yükseltirken delegasyonlara çıkarların ötesinde bir dünya olduğunu ve gelecek nesiller yararına yapılması gerekenleri hatırlatmaktadır.

Bu bağlamda buraya kadar vurgulanan noktalar üzerinden çevre örgütlerinin etkinliği tam olarak ölçülemese de çevresel muhafazaya ilişkin katkıları şu şekilde sıralanabilir:

- Antarktika'nın çevre sorunları hakkında halkı bilinçlendirmek ve kamuoyu katılımının önünü açmak ve kolaylaştırmak,

- Çevresel muhafazayı daimî bir öncelik haline getirerek taraf devletlerin dikkatini, özellikle az ilgi gören, gündemde olmayan ve acil çözüm gerektiren konulara çekmek,

- Taraf devletlerin ve kamuoyunun çevre koruma standartlarına yönelik ilgisini arttırmak ve bunu yaparken, insan-doğa ilişkine farklı bir açıdan bakılmasını sağlamak. ${ }^{69}$

\section{Sonuç}

Bu çalışma birçok çevre sivil toplum örgütünden oluşan ASOC'nin küresel Antarktika siyasetinde oynadığ rolün gelişimini nitelik ve nicelik olarak ele almıştır. Analiz sonucunda elde edilen bulgulara göre 1970'lerde toplantı odalarının kapılarının dışında lobicilik yapma zamanından 2010'larda bir delege koltuğunda lobiciliğin ilk günleri arasında pek çok şey değişmiştir. Günümüzde ise ASOC gibi çevre örgütleri medyanın ilgisini, kamuoyu dikkatini, bilimsel yayınlarını ve ulusal hükümetlerle istişare yönetimi birer araç olarak kullanmaktadır.

Genel açıdan bakıldığında zihin entelektüelleşmekten hoşlanır ancak yapılan tüm değerlendirme ve analizlerin sınırları olduğunu unutmamak önemlidir. Bu çalışmalar doğaları gereği, yalnızca ölçülebilir olanı yakalayabilirler. Yaşam için en değerli olan şeylerin çoğu paha biçilemez ve ölçülemezdir ve bu nedenle değerlendirme ve analizlerin sonuçlarında görünmeyecektir. Bu bağlamda Antarktika'nın insanlık için sahip olduğu en büyük armağanlardan biri, el değmemiş doğası ve benzersiz ekosistemiyle, bir umut sembolü ve aynı

\footnotetext{
${ }^{68}$ Detaylar için ASOC raporlarına ve infografiklerine bknz.: https://www.asoc.org/explore/reports, (03.01.2021).

${ }^{69}$ Tina Tin, "Environmental advocacy in the Antarctic Treaty System - a personal view from the 2000s"', 426.
} 
zamanda ilham kaynağı olmasıdır. Bununla birlikte kıta ekosistemi tüm ekosistemlerle bağlantılı kilit bir noktadadır. Dolayısıyla kıta çevresinin muhafazasının kapsamlı bir şekilde sağlanması, küresel çapta önemli ve gereklidir. Her ne kadar ulusal çıkarlar varlığını korusa da askeri silahları bir kenara bırakarak tüm insanlığın yararına iş birliği yapmayı kabul etmek ve AA'nın imzalanması dünyanın başka birçok yerinde ve başka zamanlarda elde edilememiş bir başarıdır. Bu başarının sürdürülmesinde hükümet-dışı çevre örgütlerinin en yüksek çevre standartları için ısrarlı talebi, vahşi bir kıtanın ve okyanusun korunmasında cesaretlendirici olmaktadır. İnsan ve doğa ilişkisinin gelecek nesiller yararına sürdürülebilmesi için çalışmanın mümkün olduğunu göstermektedir.

Bu noktada ASOC Antarktika'nın yönetiminde çevresel muhafazanın bir öncelik haline getirilmesi, bu önceliğin bilinçlendirilmiş bir kamuoyu tarafından desteklenmesi, ulusal çıkarların yanında gelecek nesillerin de düşünülmesi konusunda savunuculuk faaliyetleriyle etkili olmaktadır. Günümüzde özellikle iklim değişikliği sebebiyle gittikçe artan çevresel hassasiyetler ve kıta ekolojisindeki değişimlerin küresel sonuçları, ASOC'nin Antarktika siyasetindeki varlığını öne çıkartan etkenlerdir. Bu bağlamda ASOC resmi toplantılarda yer alarak, bilimsel araştırma yürütüp elde ettiği verileri paylaşarak, teknik ve stratejik destek sağlayarak, delegasyonları ve kamuoyunu acil düzenleme gerektiren konularla ilgili bilgilendirerek Antarktik ilişkilerinde çevre vizyonunun ön plana çıkartılmasında en etkili oyuncu olmaya devam etmektedir.

\section{Teşekkür}

Bu çalışma 2020 yılında gerçekleştirilen 4. Kutup Bilimleri Çalıştayı ve Şenliği’nde sunulan bildiri üzerinden geliştirilmiştir. Süreç içindeki destekleri için TÜBİTAK MAM KARE'ye teşekkür ederim.

\section{Kaynaklar}

Albatrosların ve Petrellerin Korunması Anlaşması. https://www.acap.aq, (18.01.2021).

Antarktik Ayı Balıklarını Koruma Sözleşmesi. https://ats.aq/e/key-documents.html, (09.01.2021).

Antarktik Maden Kaynakları Faaliyetlerinin Düzenlenmesine İlişkin Sözleşme. https://www.ats.aq/e/key-documents.html, (18.01.2021).

Antarktika Antlaşmas1 (AA). https://www.ats.aq/e/antarctictreaty.html, (09.01.2021).

Antarktika Antlaşması Çevre Protokolü. https://www.ats.aq/e/protocol.html, (16.01.2021). 
ASOC. "Implications of Antarctic Krill Fishing in ASMA No. 1 - Admiralty Bay IP 54." ATCM XXXV. Hobart, June 11-20, 2012b.

ASOC. "Making Tangible Progress on a Strategic Vision for Antarctic Tourism IP 80." ATCM XXXIV. Buenos Aires, June 20-July 01, 2011, 2010.

ASOC. "Management Implications of Tourist Behaviour IP 67." ATCM XXXVI. Brussels, May 20$29,2013 \mathrm{c}$.

ASOC. "Report of the Antarctic and Southern Ocean Coalition (ASOC) IP 84". ATCM XXII. The Hague, May 25-June 05, 1998.

ASOC. "Report of the Antarctic and Southern Ocean Coalition (ASOC) IP 21". SATCM VII, Tromsø, September 11-15, 2000.

ASOC. "Report of the Antarctic and Southern Ocean Coalition (ASOC) IP 66 Rev.1." ATCM XXVII. Cape Town, May 24-June 04, 2004.

ASOC. "Report of the Antarctic and Southern Ocean Coalition (ASOC) IP 85". ATCM XXXV. Hobart, June 11-20, 2012a.

ASOC. "Strengthening the CEE Process IP 84". ATCM XXX, New Delhi, April 30-May 11, 2007a.

ASOC. "Tourism and Land-based Facilities in Antarctica IP 23 Rev.1." ATCM XXXII. Baltimore, April 06-17, 2009a.

ATCM XXXVII. "Antarctic Trial of WWF's Rapid Assessment of Circum-Arctic Ecosystem Resilience". Conservation Planning Tool. https://www.worldwildlife.org/publications/racerrapid-assessment-of-circum-arctic-ecosystem-resilience--2, (24.12.2020).

Australia. "Subsidiary Group on Management Plans": France, "Environmental Monitoring and Reporting; Czech Republic, "Response to the Comments"; New Zealand, "Intersessional Report". https://www.ats.aq/devAS/ToolsAndResources/AntarcticTreatyDatabase?lang=e, (08.12.2020).

Bastmeijer, C.J. "Implementing the Antarctic Environmental Protocol: Supervision of Antarctic Activities." Tilburg Foreign Law Review, no. 1 (2003): 407-438.

Bastmeijer, C.J. "Implementing the Antarctic Environmental Protocol: Supervision of Antarctic Activities." Tilburg Foreign Law Review, no. 1 (2003): 407-438.

Suter, K. Antarctica: Private Property or Public Heritage?. London: Zed Books, 1991.

Barnes, J.N. "Legal Aspects of Environmental Protection in Antarctica." in The Antarctic Legal Regime, eds. C.C. Joyner and S.K. Chopra, 241-268. Dordrecht: Martinus Nijhoff, 1988.

Clark, M. "The Antarctic Environmental Protocol: NGOs in the Protection of Antarctica." in Environmental NGOs in World Politics, eds. T. Prince and M. Finger, 160-185. New York: Routledge, 1994.

Convey, P., K.A. Hughes and T. Tin. "Continental Governance and Environmental Management Mechanisms Under the Antarctic Treaty System Sufficient for the Biodiversity Challenges of this Century?" Biodiversity 13 (2012): 3-4.

Convey, P., K.A. Hughes and T. Tin. "Continental Governance and Environmental Manage- ment Mechanisms Under the Antarctic Treaty System Sufficient for the Biodiversity Challenges of this Century?" Biodiversity 13, no. 3-4 (2012): 241.

Deniz Canlı Kaynaklarının Korunması Hususunda Sözleşme. https://www.ccamlr.org/en/organisation/camlr-convention-text, (16.01.2021). 
Dodds, K. "Governing Antarctica: Contemporary Challenges and the Enduring Legacy of the 1959 Antarctic Treaty." Global Policy, no. 1 (2010): 108-115.

Doruk, E. "'Governing of Global Commons in the Scope of International Regime." Yayımlanmamış Doktora Tezi, Ege Üniversitesi, 2018.

ECO. "A Publication of Non-Governmental Environmental Organizations at the XXXIV Commission on the Conservation of Antarctic Meeting Living Resources Meeting". 21 Oct. 2015.

ECO. "A Publication of Non-Governmental Environmental Organizations at the XLII Consultative Meeting of the Antarctic Treaty". July 1-11, 2019.

ECO. "A Publication of Non-Governmental Environmental Organizations at the XXXVI Commission on the Conservation of Antarctic Meeting Living Resources Meeting"'. Oct. 16-27, 2017.

ECO. "A Publication of Non-Governmental Environmental Organizations at the XXXVII Commission on the Conservation of Antarctic Meeting Living Resources Meeting'". 8 Oct. 22-Nov. 2, 2018.

ECO. "A Publication of Non-Governmental Organizations at the XXIX Consultative Meeting of the Antarctic Treaty." Edinburgh, no. 3, June 12-23, 2006.

ECO. "A Publication of Non-Governmental Organizations at the XXVII Consultative Meeting of the Antarctic Treaty." Cape Town, no. 3, May 24-June 4, 2004.

ECO. "A Publication of Non-Governmental Organizations at the XXX Consultative Meeting of the Antarctic Treaty." New Delhi, no. 3, April 30-May 11, 2007 a.

ECO. "A Publication of Non-Governmental Organizations at the XXX Consultative Meeting of the Antarctic Treaty." New Delhi, no. 3, April 30-May 11, $2007 \mathrm{~b}$.

ECO. "A Publication of Non-Governmental Organizations at the XXX Consultative Meeting of the Antarctic Treaty." New Delhi, no. 3, April 30-May 11, $2007 \mathrm{~b}$.

ECO. "A Publication of Non-Governmental Organizations at the XXXV Consultative Meeting of the Antarctic Treaty." Hobart, no. 3, June 11-20, 2012a.

ECO. "A Publication of Non-Governmental Organizations at the XXXV Consultative Meeting of the Antarctic Treaty." Hobart, no. 3, June 11-20, 2012b.

ECO. "An NGO Newspaper Published for the XXII Antarctic Treaty Consultative Meeting." volume LXXXXV, no. 3, Tromso, May 25-June 6, 1998.

ECO. “ATCM XXV.” Warsaw, no. 3, September 13, 2002.

ECO. “ATCM XXV.” Warsaw, no. 3, September 13, 2002.

Greenpeace N N. https://wayback.archive-it.org/9650/20200424150737/http://p3raw.greenpeace.org/new-zealand/en/take-action/Take-action-online/Save-the-Last-Ocean/, (08.12.2020).

Herr, R. "The Changing Roles of Non-governmental Organizations in the Antarctic Treaty System." in The Effectiveness and Legitimacy of the Antarctic Treaty System, eds. O.S. Stokke and D. Vidas, 91-119. Cambridge: Cambridge University Press, 1996.

Howkins, A. "Politics and environmental regulation in Antarctica: a historical perspective." in Handbook on the Politics of Antarctica, eds. Klaus Dodds, Alan D. Hemmings and Peder Roberts, 337-350. Cheltenham: Edward Elgar Publishing, 2017.

Kimball, L. "The Role of Non-Governmental Organizations in Antarctic Affairs." in The Antarctic Legal Regime, eds. C.C. Joyner and S.K. Chopra, 33-63. Dordrecht: Martinus Nijhoff, 1988. 
Neufeld, E., J. O’Reilly, R. Summerson and T. Tin, "Valuing Antarctica: emerging views from international studies." in Antarctic Futures, eds. Tina Tin, Daniela Liggett, Patrick T. Maher, Machiel Lamers, 233-252. Dordrecht: Springer, 2014.

Nagtzaam, G. The Making of International Environmental Treaties. Neoliberal and Constructivist Analyses of Normative Evolution. Cheltenham: Edward Elgar, 2009.

Orheim, O. A., N. Gilbert, "Managing the Antarctic Environment: The Evolving Role of the Committee for Environmental Protection." in Science Diplomacy. Antarctica, Science, and the Governance of International Spaces, eds. P.A. Berkman, M.A. Lang, D.W.H. Walton, and O.R. Young, 209-221. Washington, DC: Smithsonian Institution Scholarly Press, 2011.

Roura, R.M. "The Antarctic and Southern Ocean Coalition - ASOC." in The Encyclopedia of the Antarctic, ed. B. Riffenburgh, 41-43. New York: Routledge, 2007.

Roura, R.M. and T. Tin. "Strategic Thinking and the Antarctic Wilderness: Contrasting Alternative Futures." in Antarctic Futures: Human Engagement with the Antarctic Environment, eds. T. Tin, D. Ligget, P. Maher and M. Lamers, 253-271. Dordrecht: Springer, 2014.

Roura, R.M. and Ibáñez E. del Acebo. "Percepción ambiental en el Oceáno Austral: La Antártida real, imaginaria y posible." in El habitar urbano: Pensamiento, imaginación y límite, ed. Ibáñez E. del Acebo, 555-599. Buenos Aires: Universidad del Salvador, 2000.

Roura, R. M. "The Antarctic and Southern Ocean Coalition - ASOC." in The Encyclopedia of the Antarctic, ed. B. Riffenburgh, 41-43. New York: Routledge, 2007.

The Antarctica Blog. http://antarcticablog.blogspot.com/,\%20http://antarcticocean.org/supporters/, (22.11.2020).

Tin, T., R. Roura and M. Perrault, "Enhancing the Environmental Legacy of the International Polar Year 2007-2008." Eos Transactions AGU 87, no. 52 (2006).

Tin, T., K. Bastmeijer, J. O'Reilly and P. Maher. "Public Perception of the Antarctic Wilderness: Surveys from an Educated, Environmentally Knowledgeable European Community," in Science and Stewardship to Protect and Sustain Wilderness Values: Ninth World Wilderness Congress Symposium; November 6-13, 2009; Meridá, Yucatán, Mexico, comps. A. Watson, J. Murrieta-Saldivar, and B. McBride, 109-117.

Tin, T. " Environmental advocacy in the Antarctic Treaty System - a personal view from the 2000s". The Polar Journal 3, no. 2 (2013): 415-430.

Uluslararası Balina Avcılığının Düzenlenmesi Sözleşmesi. https://iwc.int/convention, (09.01.2021).

Wapner, P. Environmental Activism and World Civic Politics. Albany: SUNY Press, 1996. 